\title{
TERNARY SURFACE COMPLEX: COADSORPTION OF Cu(II), Zn(II), Cd(II) AND NITRILOTRIS(METHYLENE PHOSPHONIC) ACID ONTO BOEHMITE
}

\author{
María C. Zenobi* y Elsa H. Rueda \\ Departamento de Química, Universidad Nacional del Sur, Avda. Alem 1253, (B8000CPB) Bahía Blanca, Argentina
}

Recebido em 27/4/11; aceito em 16/9/11; publicado na web em 8/11/11

\begin{abstract}
This work studies the effect of NTMP (nitrilotris(methylenephosphonic acid)) on the adsorption of $\mathrm{Cu}$ (II), $\mathrm{Zn}$ (II), and Cd(II) onto boehmite in the $\mathrm{pH}$ range 5-9.5. The data were analyzed using the 2-pK constant capacitance model (CCM) assuming ternary surface complex formation. Under stoichiometric conditions, NTMP is more effective for removing $\mathrm{Cu}$ (II) than $\mathrm{Zn}$ (II) from solution and the contribution of ternary surface complexes are important to model the adsorption of both metals. Under nonstoichiometric conditions and high surface loading with a $\mathrm{Me}(\mathrm{II}) / \mathrm{NTMP}$ ratio of 1:5, $\mathrm{Cu}$ (II) and $\mathrm{Zn}$ (II) adsorption is significantly suppressed. In the case of $\mathrm{Cd}(\mathrm{II})$ the free metal adsorption is the most dominant species.
\end{abstract}

Keywords: boehmite; Me(II)-phosphonate adsorption; ternary surface complexes.

\section{INTRODUCTION}

Metal contamination continues to presents a major environmental problem. ${ }^{1}$ Metals are introduced into aquatic systems as a result of the weathering of soils and rocks, from volcanic eruptions, and from a variety of human activities. ${ }^{2-4}$ The biggest source of heavy metal pollution is known to be industrialization. ${ }^{5,6}$ Furthermore, high concentrations of heavy metals enter the aquatic system by release of industrial cooling water into rivers, dumping of sewage sludge, and through wet and dry deposition.

Complexation can drastically alter adsorption characteristics, and hence the mobility, of metals in the environment. The importance of such effects depends on the concentrations of metal-ligand complexes in environmental media and their inherent reactivity. ${ }^{7-11}$

In many instances, the aqueous concentration of a metal is controlled by adsorption reactions with the surrounding geochemical phases. The formation of metal-ligand complexes can prevent metal adsorption onto the solid matrix, keeping the metal in the dissolved phase and rendering it highly mobile. ${ }^{12,13}$ Since metals, ligands, and oxide surfaces can all possess multiple sites of coordination; the possibility exists for the creation of a ternary complex. ${ }^{14-21}$

Therefore, it is very important to understand under which conditions heavy metals are mobilized or immobilized. The overall purpose of this research was to study the adsorption of NTMP (nitrilotris(methyleneph osphonic acid)), and Me-NTMP using boehmite as a solid phase and to give special focus on the influence of this phosphonate on the adsorption behavior of $\mathrm{Cu}(\mathrm{II}), \mathrm{Zn}$ (II), and $\mathrm{Cd}(\mathrm{II})$. To elucidate the competitive effects among boehmite, metals and NTMP; and the possible use of the constant capacity double layer model (CCM) to predict adsorption from double-solute systems using equilibrium constants obtained from single-solute systems, a study of adsorption of these metal ions in presence of NTMP was carried out. The effects of environmental conditions such as $\mathrm{pH}$ variation, the concentration of solutes and various metal-ligand relationships were specifically investigated.

\section{EXPERIMENTAL}

\section{Materials}

The boehmite used in this study was obtained at our laboratory

*e-mail: mzenobi@criba.edu.ar as described by Zenobi et al.. ${ }^{19}$ The surface area was determined to be $200 \mathrm{~m}^{2} / \mathrm{g}$ as measured by BET $\mathrm{N}_{2}$ adsorption using a Quantachrome NOVA 1200e analyzer. NTMP was obtained from Aldrich Chemicals.

All the solutions were prepared using reagent-grade chemicals and deionized distilled and boiled water. Metal ion solutions were prepared by dissolving the metal nitrate salts in distilled water.

\section{Adsorption experiments}

In all cases, the adsorption experiments were carried out in a sealed cylindrical beaker fitted with a thermostat water jacket and having a total volume of $50 \mathrm{~mL}$.

$\mathrm{Me}(\mathrm{II})$ solutions at concentrations of $1 \times 10^{-5}, 5 \times 10^{-5}$ and $1 \times 10^{-4} \mathrm{M}$, and NTMP solutions at concentrations of $5 \times 10^{-5}$, $1 \times 10^{-4}$ and $5 \times 10^{-4} \mathrm{M}$, were used for the adsorption study. The $\mathrm{Me}(\mathrm{II})-\mathrm{NTMP}$ solutions were pre-equilibrated prior to their addition to the boehmite suspension. The boehmite concentration used in all experiments was $1 \mathrm{~g} / \mathrm{L}$. $\mathrm{NaNO}_{3}$ was employed to provide an ionic strength of $0.1 \mathrm{M}$. Carbon dioxide was excluded by purging the suspension with $\mathrm{N}_{2}$. Suspension $\mathrm{pH}$ was adjusted by adding trace amounts of $\mathrm{HNO}_{3}$ or $\mathrm{NaOH}$ to keep the $\mathrm{pH}$ value in the range 5 to 9.5. NTMP and Me(II) adsorption was calculated as the difference between the total added ligand and metals, and that measured in the supernatant after $2 \mathrm{~h}$ of equilibrium at $30 \pm 0.2^{\circ} \mathrm{C}$. The suspensions were filtered through a $0.45 \mu \mathrm{m}$ cellulose nitrate filters (Osmonics) prior to analysis.

Dissolved $\mathrm{Cu}, \mathrm{Zn}$ and $\mathrm{Cd}$ concentrations in acidified supernatant were measured by ICP-OES (inductively coupled plasma) emission spectrometry with a Shimadzu Sequential 1000 model III atomic emission spectrometer.

The remaining NTMP in the supernatant was measured as total phosphorous, after digestion for $2 \mathrm{~h}$ using potassium peroxodisulfate at $100{ }^{\circ} \mathrm{C}$, by the molybdenum blue colorimetric test at $880 \mathrm{~nm}$ with a UV-V Cecil 2021 spectrometer.

\section{Modeling adsorption data}

All experimental data were analyzed using the $2-\mathrm{p} K$ constant capacitance model (CCM). The concepts and assumptions underlying the model have been previously discussed in earlier studies. ${ }^{22-24}$ 
The model describing the acid/base reactions at the boehmite surface is given by the following reactions, intrinsic constants, surface site density and specific capacitance:

$$
\begin{array}{ll}
\equiv \mathrm{Al}-\mathrm{OH}+\mathrm{H}^{+} \leftrightarrows \equiv \mathrm{Al}-\mathrm{OH}_{2}^{+} & \log \mathrm{K}_{\mathrm{a} 1}=7.47 \\
\equiv \mathrm{Al}-\mathrm{OH} \leftrightarrows \equiv \mathrm{Al}-\mathrm{O}^{-}+\mathrm{H}^{+} & \log \mathrm{K}_{\mathrm{a} 2}=-9.81 \\
\mathrm{C}=0.92 \mathrm{~F} / \mathrm{m}^{2} & \mathrm{~S}_{\mathrm{T}}=1.7 \text { sites } / \mathrm{nm}^{2}
\end{array}
$$

These data were taken from Laiti and Öhman. ${ }^{25}$

Model calculations and optimization of equilibrium constants for adsorption reactions were performed by the nonlinear least-squares optimization program FITEQL 3.2. Technical details of this program were provided by Westall and Herbelin. ${ }^{26}$ The values of these stability constants were used to adjust the different experimental adsorption edges. The data were modeled considering only mononuclear complex formation for Me(II), NTMP, and Me(II)-NTMP adsorption. The following generalized reactions represent adsorption stoichiometries:

$\equiv \mathrm{AlOH}+\mathrm{L}^{6-}+(n+1) \mathrm{H}^{+} \rightarrow \equiv \mathrm{Al}-\mathrm{L}-\mathrm{H}^{(6-n-1)-n}+\mathrm{H}_{2} \mathrm{O}$

$\equiv \mathrm{AlOH}+\mathrm{Me}^{2+} \rightarrow \equiv \mathrm{AlOMe}^{2+}+\mathrm{H}^{+}$

$\equiv \mathrm{AlOH}+\mathrm{Me}^{2+}+\mathrm{L}^{6-}+(n+1) \mathrm{H}^{+} \rightarrow \equiv \mathrm{Al}-\mathrm{LH}_{n} \mathrm{Me}^{(6-n-2-1)-}+\mathrm{H}_{2} \mathrm{O}$

where $\mathrm{L}^{6-}$ is the deprotonated ligand $\left(\mathrm{NTMP}^{6-}\right)$ and $\mathrm{Me}$ is the divalent metal. Table 1 gives the surface complexation reactions and the values of the equilibrium constants used for modeling the experimental data. Equilibrium constants for the selected surface reactions were optimized for each data set, and this unique set of constants was then used for all model simulations.

These surface constants were entered into a chemical speciation program MINEQL+3.0 to predict NTMP, Me(II), and Me(II)-NTMP sorption. ${ }^{27}$

Table 1. Equilibrium constant describing the adsorption of Me, NTMP, and Me complexes of NTMP to boehmite, fitted by FITEQL $\left(\mathrm{I}=0.1 \mathrm{M} \mathrm{NaNO}_{3}, 30^{\circ} \mathrm{C}\right)$

\begin{tabular}{lc}
\hline Surface complexation reactions & $\log \mathrm{K}$ \\
\hline$\equiv \mathrm{Al}-\mathrm{OH}+\mathrm{L}^{6-}+\mathrm{H}^{+} \leftrightarrows \equiv \mathrm{Al}-\mathrm{L}^{5-}+\mathrm{H}_{2} \mathrm{O}$ & 24.25 \\
$\equiv \mathrm{Al}-\mathrm{OH}+\mathrm{L}^{6-}+2 \mathrm{H}^{+} \leftrightarrows \equiv \mathrm{Al}-\mathrm{LH}^{4-}+\mathrm{H}_{2} \mathrm{O}$ & 30.05 \\
$\equiv \mathrm{Al}-\mathrm{OH}+\mathrm{L}^{6-}+3 \mathrm{H}^{+} \leftrightarrows \equiv \mathrm{Al}-\mathrm{LH}_{2}{ }^{3-}+\mathrm{H}_{2} \mathrm{O}$ & 35.65 \\
$\equiv \mathrm{Al}-\mathrm{OH}+\mathrm{L}^{6-}+4 \mathrm{H}^{+} \leftrightarrows \equiv \mathrm{Al}-\mathrm{LH}_{3}^{2-}+\mathrm{H}_{2} \mathrm{O}$ & 40.45 \\
$\equiv \mathrm{Al}-\mathrm{OH}+\mathrm{Cu}^{++} \leftrightarrows \equiv \mathrm{Al}-\mathrm{OCu}^{+}+\mathrm{H}^{+}$ & $-0.132 \pm 0.04^{a}$ \\
$\equiv \mathrm{Al}-\mathrm{OH}+\mathrm{Cu}^{2+}+\mathrm{L}^{6-}+\mathrm{H}^{+} \leftrightarrows \equiv \mathrm{Al}^{-} \mathrm{LCu}^{3-}+\mathrm{H}_{2} \mathrm{O}$ & 30.71 \\
$\equiv \mathrm{Al}-\mathrm{OH}+\mathrm{Cu}^{2+}+\mathrm{L}^{6-}+2 \mathrm{H}^{+} \leftrightarrows \equiv \mathrm{Al}-\mathrm{LHCu}^{--}+\mathrm{H}_{2} \mathrm{O}$ & 36.71 \\
$\equiv \mathrm{Al}-\mathrm{OH}+\mathrm{Zn}^{++} \leftrightarrows \equiv \mathrm{Al}-\mathrm{OZn}^{+}+\mathrm{H}^{+}$ & $-1.541 \pm 0.07^{a}$ \\
$\equiv \mathrm{Al}-\mathrm{OH}+\mathrm{Zn}^{2+}+\mathrm{L}^{6-}+\mathrm{H}^{+} \leftrightarrows \equiv \mathrm{Al}-\mathrm{LZn}^{3-}+\mathrm{H}_{2} \mathrm{O}$ & 29.70 \\
$\equiv \mathrm{Al}-\mathrm{OH}+\mathrm{Cd}^{++} \leftrightarrows \equiv \mathrm{Al}-\mathrm{OCd}^{+}+\mathrm{H}^{+}$ & $-2.441 \pm 0.05^{a}$ \\
$\equiv \mathrm{Al}-\mathrm{OH}+\mathrm{Cd}^{2+}+\mathrm{L}^{6-}+\mathrm{H}^{+} \leftrightarrows \equiv \mathrm{Al}_{-}-\mathrm{LCd}^{3-}+\mathrm{H}_{2} \mathrm{O}$ & 27.00 \\
$\equiv \mathrm{Al}-\mathrm{OH}+\mathrm{Cd}^{2+}+\mathrm{L}^{6-}+2 \mathrm{H}^{+} \leftrightarrows \equiv \mathrm{Al}^{-\mathrm{LHCd}^{2-}}+\mathrm{H}_{2} \mathrm{O}$ & 33.00 \\
$\equiv \mathrm{Al}-\mathrm{OH}+\mathrm{Cd}^{2+}+\mathrm{L}^{6-}+3 \mathrm{H}^{+} \leftrightarrows \equiv \mathrm{Al}-\mathrm{LH}_{2} \mathrm{Cd}^{-}+\mathrm{H}_{2} \mathrm{O}$ & 38.20 \\
\hline
\end{tabular}

${ }^{a}$ Taken from ref. 19

Stability constants for NTMP protonation and for Me(II)-NTMP complex formation were taken from Deluchat et al. (Table 2) ${ }^{28}$ NTMP, $\mathrm{Me}(\mathrm{II})$, and $\mathrm{Me}$ (II)-NTMP adsorption data were modeled by defining the minimum number of surface species that consistently yielded a

\begin{tabular}{|c|c|c|c|}
\hline \multicolumn{4}{|c|}{ Protonation constants $\left(0.1 \mathrm{M} \mathrm{NaNO}_{3}, 30^{\circ} \mathrm{C}\right)^{a}$} \\
\hline $\log K_{1}$ & & & 12.50 \\
\hline $\log K_{2}$ & & & 7.22 \\
\hline $\log K_{3}$ & & & 5.90 \\
\hline $\log K_{4}$ & & & 4.59 \\
\hline $\log K_{5}$ & & & 1.6 \\
\hline $\log K_{6}$ & & & 0.5 \\
\hline \multicolumn{4}{|c|}{ Complexation constants $\left(0.1 \mathrm{M} \mathrm{NaNO}_{3}, 30^{\circ} \mathrm{C}\right)^{b}$} \\
\hline & & $\log K$ & $\log \beta$ \\
\hline \multirow[t]{5}{*}{$\mathrm{Cu}(\mathrm{II})$} & MeL & 17.40 & \\
\hline & MeHL & 6.35 & 23.78 \\
\hline & $\mathrm{MeH}_{2} \mathrm{~L}$ & 4.57 & 28.36 \\
\hline & $\mathrm{MeH}_{3} \mathrm{~L}$ & 3.46 & 31.8 \\
\hline & $\mathrm{MeH}_{4} \mathrm{~L}$ & 1.4 & 33.3 \\
\hline \multirow[t]{5}{*}{$\mathrm{Zn}(\mathrm{II})$} & MeL & 16.3 & \\
\hline & MeHL & 6.1 & 22.5 \\
\hline & $\mathrm{MeH}_{2} \mathrm{~L}$ & 4.89 & 27.3 \\
\hline & $\mathrm{MeH}_{3} \mathrm{~L}$ & 4.0 & 31.38 \\
\hline & $\mathrm{MeH}_{4} \mathrm{~L}$ & 2.5 & 33.8 \\
\hline \multirow[t]{4}{*}{$\mathrm{Cd}(\mathrm{II})$} & MeL & 12.2 & \\
\hline & MeHL & 7.16 & 19.4 \\
\hline & $\mathrm{MeH}_{2} \mathrm{~L}$ & 5.68 & 25.0 \\
\hline & $\mathrm{MeH}_{3} \mathrm{~L}$ & 4.13 & 29.2 \\
\hline
\end{tabular}
good fit for all data.
Table 2. Speciation of NTMP and metal complexes of NTMP ${ }^{a}$

\section{RESULTS AND DISCUSSION}

In these experiments both NTMP and Me(II) concentrations were measured. The experimental data of the amounts of phosphonic acid and metal adsorbed for every Me(II)-NTMP-combination were plotted separately, revealing the influence of phosphonic acid on the metal adsorption and vice versa.

The adsorption studies of Me (II)-NTMP were performed in stoichiometric and non-stoichiometric conditions.

\section{Stoichiometric conditions}

The adsorption edges for both Cu(II)-NTMP and Zn(II)-NTMP systems at $5 \times 10^{-4} \mathrm{M}$ high solution concentrations are shown in Figure 1. Under these conditions, only $\mathrm{Cu}$ (II) and $\mathrm{Zn}$ (II) metals are considered. Cd(II) was excluded due to the low solubility of the Cd-NTMP complex.

At low $\mathrm{pH}$ values a significant increase in $\mathrm{Cu}$ (II) and $\mathrm{Zn}$ (II) adsorption can be noted in the presence of NTMP $5 \times 10^{-4} \mathrm{M}$ (full lines in Figure 1) as compared with $\mathrm{Me}$ (II) adsorbed onto boehmite in the absence of NTMP (open circles Figure 1). The ligand effect is more pronounced for $\mathrm{Zn}$ (II) than for $\mathrm{Cu}$ (II), where this is related to the values of the constants of both complexes in solution (Table 2). At $\mathrm{pH} \approx 6,7$ the adsorption of both $\mathrm{Cu}(\mathrm{II})$ and $\mathrm{Zn}$ (II) reaches a maximum and then decrease as $\mathrm{pH}$ increases. At low $\mathrm{pH}$ values the model predicts a higher affinity of the boehmite surface by complexed $\mathrm{Me}$ (II) than the metal ion in its free form. Also, the model prediction shows that at higher $\mathrm{pH}$ adsorption of free metal $\left(\equiv \mathrm{AlOMe}^{+}\right)$is the dominant species. However, it is evident that from $\mathrm{pH} 7$ the adsorbed $\mathrm{Cu}$ exists mainly in its free form while, whereas in the case of $\mathrm{Zn}$ at a $\mathrm{pH}$ of around 7.5, an equal contribution from both free and complexed forms is observed.

For the present study two mononuclear ternary surface complexes for the $\mathrm{Cu}$-NTMP system ( $\equiv \mathrm{AlLHCu}$ and $\equiv \mathrm{AlLCu}^{-}$) and only one for 

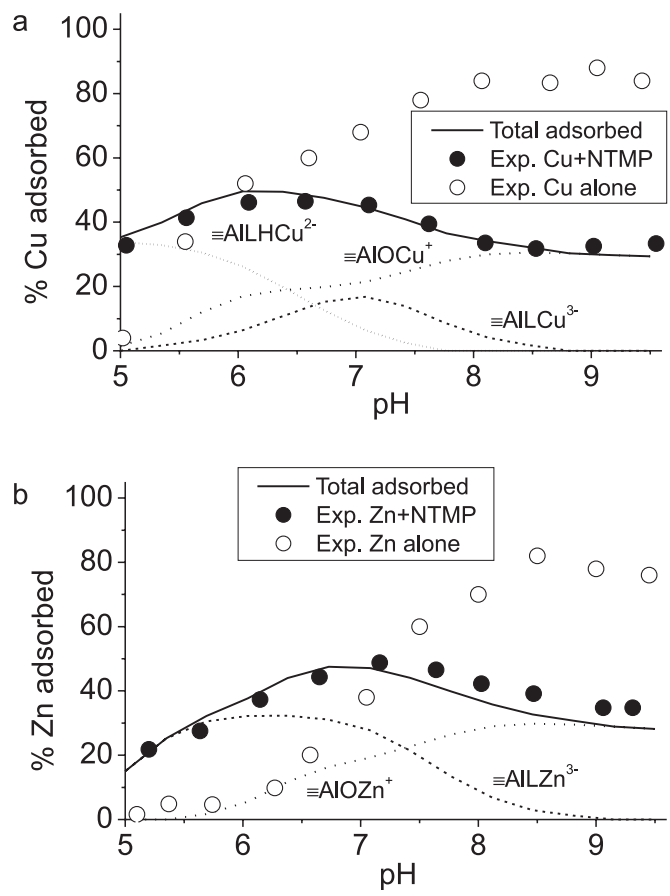

Figure 1. Percentage $\mathrm{Cu}(\mathrm{II})$ and $\mathrm{Zn}(\mathrm{II}) 5 \times 10^{-4} \mathrm{M}$ adsorbed $\mathrm{vs} \mathrm{pH}$ in the presence of NTMP $5 \times 10^{-4} \mathrm{M}$. The curves are calculated using the constants from Table 1. Conditions: $1 \mathrm{~g} / \mathrm{L}$ boehmite, $0.1 \mathrm{M} \mathrm{NaNO}_{3}$

the Zn-NTMP system ( $\equiv$ AlLZn ${ }^{-}$), in addition to adsorption of both $\mathrm{Me}$ (II) and NTMP in its free form, had to be considered in order to obtain a good fit of the experimental data. Both experimental data and model results suggest that, at low $\mathrm{pH}$, the ternary surface complexes are predominant whereas binary complexes $\mathrm{Me}(\mathrm{II})-\mathrm{AlOH}$ and NTMP-AlOH largely predominate at high $\mathrm{pH}$.

Both $\mathrm{Cu}$ (II) and $\mathrm{Zn}$ (II) metals in the presence of $1 \times 10^{-4}$ M NTMP (Figure 2Sb, supplementary material) show a typical bell-shaped adsorption edge. In both cases, the maximum metal adsorbed is close to $100 \%$. It is clear that $50 \%$ of the total available $\mathrm{Cu}$ (II) is immobilized by the presence of NTMP at pH 5 but only $20 \%$ of total $\mathrm{Zn}$ (II) concentration is attached to surface at this $\mathrm{pH}$. At lower $\mathrm{pH}$, the effect of ternary surface complexes in the adsorption process is higher for $\mathrm{Cu}$ than for $\mathrm{Zn}$ and the model predicts two ternary surface complexes for $\mathrm{Cu}$ (II) adsorption while only one is necessary to fit the adsorption results in the case of $\mathrm{Zn}(\mathrm{II})$. In both cases, after reaching a maximum of around $\mathrm{pH} 7$, the metal binary species $\left(\equiv \mathrm{AlOMe}^{+}\right)$dominates the adsorption.

The model predicts that $\mathrm{Cd}$ is preferably absorbed in its free form and the decrease observed from $\mathrm{pH} 8$ is lower than for $\mathrm{Cu}(\mathrm{II})$ and $\mathrm{Zn}(\mathrm{II})$.

The adsorption decrease exhibited by the three metals at the higher $\mathrm{pH}$ is due to a competitive effect between the active surface sites and the NTMP in solution for the metal ion. The immobilization of these metal ions at high $\mathrm{pH}$ is mainly regulated by the Me(II)-NTMP constant values (Table 2).

When Me(II)-NTMP concentration is $5 \times 10^{-5} \mathrm{M}, \mathrm{Me}(\mathrm{II})$ and NTMP are adsorbed predominantly in their free forms (Figures $3 \mathrm{Sa}$ and $3 \mathrm{Sb}$, supplementary material). In the presence of an excess of surface sites at $\mathrm{pH} 5$, only $20 \%$ of total $\mathrm{Cu}$ is removed while at the same $\mathrm{pH}$, the NTMP is completely adsorbed. The adsorption edge of $\mathrm{Zn}(\mathrm{II})$ in $5 \times 10^{-5} \mathrm{M} \mathrm{Zn}(\mathrm{II})-\mathrm{NTMP}$ system exhibits the same trend as the free $\mathrm{Zn}$ (II) adsorption pattern. However, in both systems the contribution of ternary surface complexes must be invoked to adjust the experimental results of $\mathrm{Cu}(\mathrm{II}), \mathrm{Zn}(\mathrm{II})$ and NTMP adsorption. Due to the high stability of the Cu-NTMP and Zn-NTMP complexes in solution at a $\mathrm{pH}$ greater than 8 , only a slight decrease in the adsorption of $\mathrm{Cu}$ (II) and $\mathrm{Zn}$ (II) is caused by the presence of NTMP. When concentration of the Cd-NTMP solution is $5 \times 10^{-5} \mathrm{M}$ the model predicts that both Cd and NTMP adsorb only in their free form.

\section{Non-stoichiometric conditions}

\section{Deficiency of surface sites}

Experimental and model results for Me(II) $1 \times 10^{-4}$ and NTMP $5 \mathrm{x}$ $10^{-4} \mathrm{M}$ adsorption onto boehmite are shown in Figure 2. Because metal concentration is five times lower than the concentration of NTMP the metal is expected to be completely complexed with NTMP in solution while the NTMP will remain mostly in its free form. For the $\mathrm{Cu}-\mathrm{NTMP}$ system experimental results indicated poor adsorption of the metal across the entire $\mathrm{pH}$ range reaching a maximum of $20 \%$ at the higher $\mathrm{pH}$. In the case of Zn-NTMP the metal adsorption is even less not exceeding 10\%. Employing the same surface complexation constants used to fit the data under stoichiometric conditions, the model predicts that the percentage of $\mathrm{Cu}$ (II) and $\mathrm{Zn}$ (II) adsorbed is practically negligible.

Deluchat et al. and Sawada et al. calculated the complexation constants of different NTMP-Me complexes with a ratio ligand/
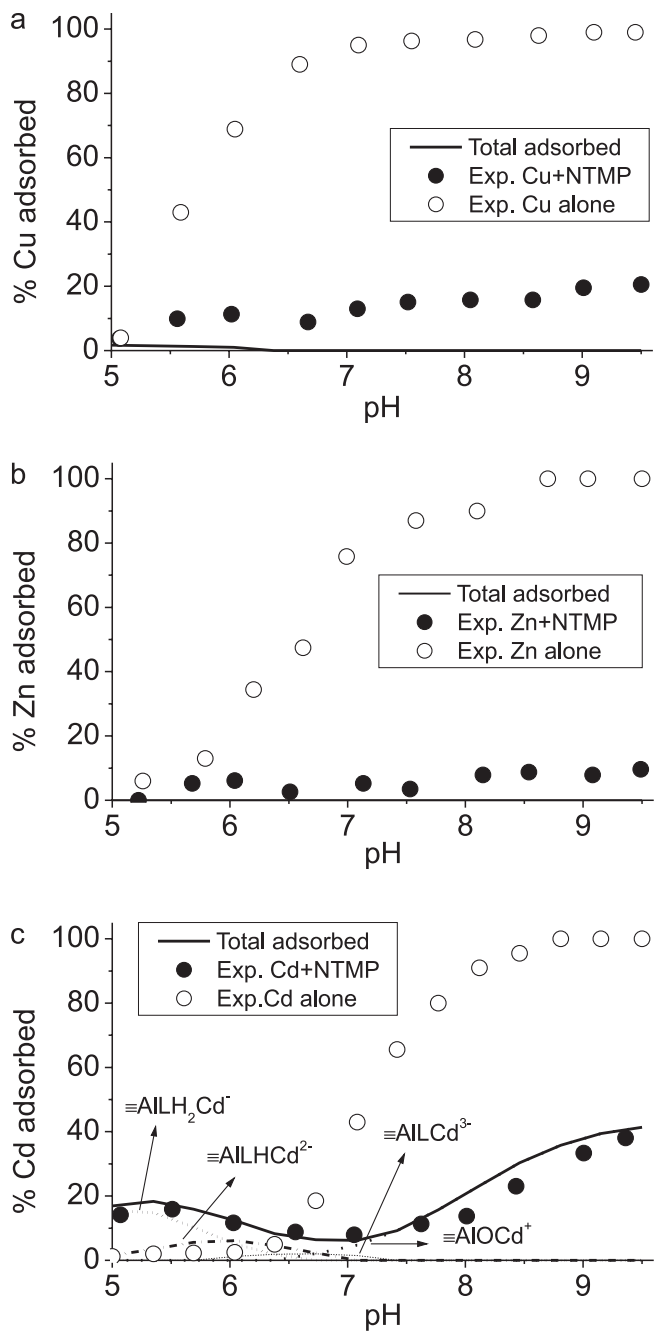

Figure 2. Percentage $\mathrm{Cu}(\mathrm{II}), \mathrm{Zn}(\mathrm{II})$ and $\mathrm{Cd}(\mathrm{II}) 1 \times 10^{-4} \mathrm{M}$ adsorbed $v$ s $\mathrm{pH}$ in the presence of NTMP $5 \times 10^{-4} \mathrm{M}$. The curves are calculated using the constants from Table 1. Conditions: $1 \mathrm{~g} / \mathrm{L}$ boehmite, $0.1 \mathrm{M} \mathrm{NaNO}_{3}$ 
metal (1/1), although no reports in the literature address other molar relationships. ${ }^{28,29}$ It is possible that the relationship used in this study, with a ligand concentration five times greater than the concentration of metal, contributes to form other complexes such as $\mathrm{M}_{2} \mathrm{~L}$ or $\mathrm{ML}_{2}$ not taken into account when modeling the experimental data thus leading to the observed deviations between the experimental results and those arising from the model. This is especially true in the case of NTMP-Cu.

For Cd $1 \times 10^{-4}$ and NTMP $5 \times 10^{-4} \mathrm{M}$ the model satisfactorily predicts the adsorption of both NTMP and Cd (II) solutes over the entire $\mathrm{pH}$ range (Figure 4Sa compares the NTMP behavior when this ligand is alone). Moreover, it is evident that, unlike $\mathrm{Cu}$ (II) and $\mathrm{Zn}$ (II), surface ternary species contribute to the adsorption of both NTMP and Cd (II). Another important aspect is that, besides the species $\equiv \mathrm{AlLCd}^{3-}$ and $\equiv \mathrm{AlLHCd}^{2-}$ already considered in the stoichiometric conditions, was necessary to introduce the species $\equiv \mathrm{AlLH}_{2} \mathrm{Cd}^{-}$to achieve a good fit for the data. In the case of Cd(II), we may assume no change in the species in solution for the excess ligand such that all experiments under stoichiometric and non stoichiometric conditions can be adjusted by using the same set of constants.

\section{Excesses of surface sites}

In this case, where the $\mathrm{L} / \mathrm{M}$ is also $5 / 1$, but at concentrations ten times lower than those considered in the previous paragraph, we note that the model adequately predicts the adsorption behavior of both ligand and metal (Figures 3 and 5Sa, supplementary material).
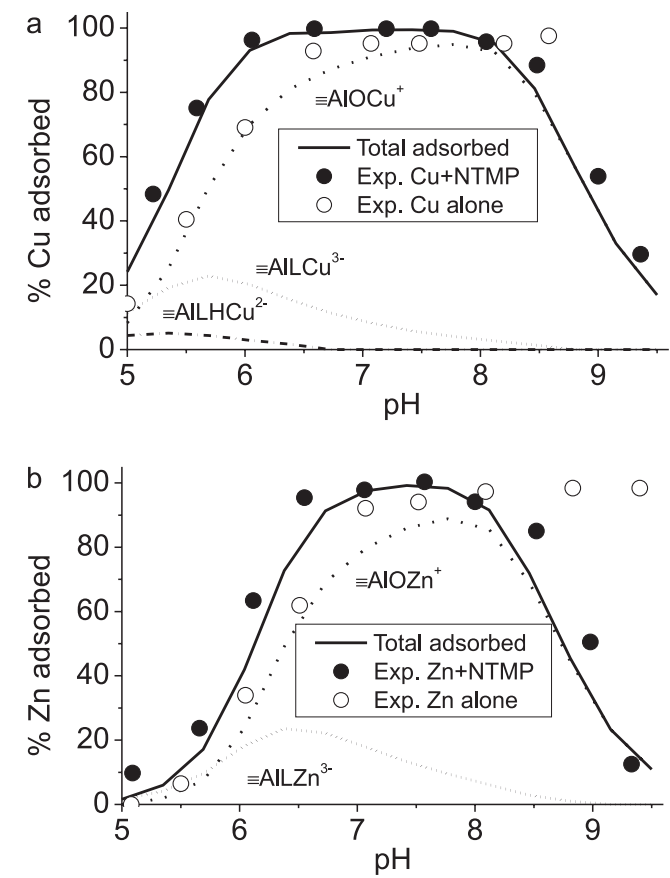

Figure 3. Percentage $\mathrm{Cu}(\mathrm{II})$ and $\mathrm{Zn}(\mathrm{II}) 1 \times 10^{-5} \mathrm{M}$ adsorbed $v \mathrm{pH}$ in the presence of NTMP $5 \times 10^{-5} \mathrm{M}$. The curves are calculated using the constants from Table 1. Conditions: $1 \mathrm{~g} / \mathrm{L}$ boehmite, $0.1 \mathrm{M} \mathrm{NaNO}_{3}$

At low surface coverages, an excess of NTMP does not have the same impact as in the case of a deficiency of surface sites. A slight increase in adsorption is observed for $\mathrm{Cu}$ (II) at $\mathrm{pH}$ below 6.5 where the ternary surface species makes an important contribution to the total metal adsorption.

At $\mathrm{pH}$ bellow 8, Zn (II) and Cd (II) (Figure 5Sb, supplementary material) did not significantly alter their behavior in the presence of NTMP, display a similar adsorption pattern with a slight increase in metal retention.
At $\mathrm{pH} 8$ the adsorption of $\mathrm{Cu}$ (II) and $\mathrm{Zn}$ (II) begins to decrease markedly through the effect of excess ligand, leading to the same percentages of adsorption found at more acidic $\mathrm{pH}$. As in previous cases, this is attributed to the increased stability of the Me-NTMP complexes in alkaline media and the lower affinity of Me-NTMP complexes for the oxide surface under this condition.

In contrast, Cd (II) (Figure 5Sb, supplementary material) does not requires the presence of ternary surface complexes to fit the experimental data, showing the same profile as the free metal adsorption. Similarly, the adsorption behavior is again the result of the consequent competition between chelation and adsorption.

Under both stoichiometric and non-stoichiometric conditions, the presence of metals has no significant effect on the NTMP adsorption edge. The adsorption level reaches the pattern followed by the free NTMP. However, it is necessary to consider the formation of ternary surface complexes to explain the phosphonate adsorption in the presence of metal ions (Figures $1 \mathrm{Sa}$ to $5 \mathrm{Sa}$, supplementary material).

\section{CONCLUSIONS}

This study provides valuable information on adsorption from $\mathrm{Me}(\mathrm{II})-\mathrm{NTMP}$ mixtures in the $\mathrm{pH}$-range of natural waters (5-9.5) and at different adsorbent concentrations. The 2-pK constant capacitance model (CCM) agreed with the overall adsorptive trends for $\mathrm{Cu}(\mathrm{II})$, $\mathrm{Zn}$ (II) and Cd(II) in the presence of stoichiometric and nonstoichiometric concentrations of NTMP under different surface coverage conditions. Experimental and model results suggest the adsorption of free metal ions and NTMP as well as ternary complexes $\equiv$ Al-NTMP-Me(II). These ternary surface complexes produce drastic changes in the adsorption trend for $\mathrm{Cu}(\mathrm{II}), \mathrm{Zn}$ (II) and $\mathrm{Cd}(\mathrm{II})$. These results are in agreement with the statement by Zenobi and Rueda, who demonstrated that the presence of 1-hydroxyethane-(1,1-diphosphonic acid) (HEDP) in natural waters could aid in the removal of those divalent metals dissolved. ${ }^{20}$ However, there is a substantial difference in the complexing behavior of HEDP and NTMP under conditions of high phosphonate/metal ratio and high surface loading. NTMP is a stronger complexing agent than HEDP and this may have a major environmental impact since it might contribute toward mobilizing $\mathrm{Cu}(\mathrm{II}), \mathrm{Zn}(\mathrm{II})$ and $\mathrm{Cd}(\mathrm{II})$ from sediments.

\section{SUPPLEMENTARY MATERIAL}

The Figures $1 \mathrm{Sa}$ to $5 \mathrm{Sa}$ (Percentage NTMP adsorbed vs pH in the presence of $\mathrm{Cu}(\mathrm{II}), \mathrm{Zn}(\mathrm{II})$ and $\mathrm{Cd}(\mathrm{II}))$, Figures $2 \mathrm{Sb}$ and $3 \mathrm{Sb}$ (Percentage $\mathrm{Cu}(\mathrm{II}), \mathrm{Zn}(\mathrm{II})$ and $\mathrm{Cd}(\mathrm{II})$ adsorbed vs $\mathrm{pH}$ in the presence of NTMP) and Figure $5 \mathrm{Sb}$ (Percentage Cd(II) $1 \times 10^{-5} \mathrm{M}$ adsorbed vs $\mathrm{pH}$ in the presence of NTMP $5 \times 10^{-5} \mathrm{M}$ ) are available free of charge at http://quimicanova.sbq.org.br, as PDF file.

\section{ACKNOWLEDGMENTS}

We are grateful to the Secretaría General de Ciencia y Tecnología (SGCyT), Universidad Nacional del Sur for financial support. We are grateful to the anonymous reviewers for constructive comments that enhanced the clarity of this manuscript.

\section{REFERENCES}

1. Damian, F.; Damian, G.; Lăcătuşu, R.; Macovei, G.; Iepure, G.; Năprădean, I.; Chira, R.; Kollar, L.; Raţă, L.; Zaharia, D. C.; Carpth. J. of Earth and Environ. Sci. 2008, 3, 85.

2. Bradl, H. B. In Heavy Metals in the Environment: Origin, Interaction and Remediation; Bradl, H. B., ed.; Elsevier, 2005, chap. 1. 
3. Das, P.; Mukherjee, S.; Sen, R.; Bioresour. Technol. 2009, 100, 4887.

4. Larocque, A. C. L.; Rasmussen, P. E.; Envir. Geol. 1998, 33, 85.

5. Allan, R.; Geochem. J. Explor. 1997, 58, 95.

6. Siegel, F. R.; Environmental Geochemistry of Potentially Toxic Metals, Springer-Verlag: Berlin, 2002, chap. 1.

7. Nowack, B.; Xue, H.; Sigg, L.; Environ. Sci. Technol. 1997, 31, 866.

8. Xue, H. B.; Sigg, L.; Anal. Chim. Acta 1994, 284, 505.

9. Xue, H.; Sigg, L.; Anal. Chim. Acta 1998, 363, 249.

10. Christensen, J. B.; Botma, J. J.; Christensen, T. H.; Water Res. 1999, 33 , 3231.

11. Christensen, J. B.; Christensen, T. H.; Environ. Sci. Technol. 1999, 33, 3857.

12. Goldstein, D.; Biophys. J. 1979, 26, 235.

13. Lamb, J. D.; Christensen, J. J.; Oscarson, J. L.; Nielsen, B. L.; Asay, B. W.; Izat, R. M.; J. Am. Chem. 1980, 102, 6820.

14. Davis, A. P. In Encyclopedia of Surface and Colloid Science; Somasundaran, P., ed.; New York, 2006.

15. Tipping, E.; Griffith, J. R.; Hilton, J.; Croat. Chem. Acta 1983, 56, 613.

16. Ludwing, C.; Schindler, P. W.; J. Colloid Interface Sci. 1995, 169, 291.

17. Ali, M. A.; Dzombak, D. A.; Geochim. Cosmochim. Acta 1996c, 60 , 5045.
18. Nowack, B.; Sigg, L.; J. Colloid Interface Sci. 1996, 177, 106.

19. Zenobi, M. C.; Hein, L.; Rueda, E.; J. Colloid Interface Sci. 2005, 284, 447.

20. Zenobi, M. C.; Rueda, E. H.; Environ. Sci. Technol. 2006, 40, 3254.

21. Hein, L.; Zenobi, M. C.; Rueda, E.; J. Colloid Interface Sci. 2007, 314, 317.

22. Stumm, W.; Hohl, H.; Dalang, F.; Croat. Chem. Acta 1976, 48, 491.

23. Stumm, W.; Kummert, R.; Sigg, L.; Croat. Chem. Acta 1980, 53, 291.

24. Goldberg, S.; Soil Sci. Soc. Am. J. 1985, 49, 851.

25. Laiti, E.; Öhman, L.-O.; J. Colloid Interface Sci. 1996, 183, 441.

26. Westall, J.; Herbelin, A.; FITEQL; Chemical Equilibrium Program; Oregon State University, 1996.

27. Schecher, W. D.; McAvoy, D. C.; MINEQL+; Chemical Equilibrium Modeling System; Environmental Research Software: Hallowell, ME, 1994.

28. Deluchat, V.; Bollinger, J. C.; Serpaud, B.; Caullet, C.; Talanta 1997, 44, 897.

29. Sawada, K.; Araki, T.; Suzuki, T.; Doi, K.; Inorg. Chem. 1989, 28, 2687. 
TERNARY SURFACE COMPLEX: COADSORPTION OF Cu(II), Zn(II), Cd(II) AND NITRILOTRIS(METHYLENE PHOSPHONIC) ACID ONTO BOEHMITE

María C. Zenobi* y Elsa H. Rueda

Departamento de Química, Universidad Nacional del Sur, Avda. Alem 1253, (B8000CPB) Bahía Blanca, Argentina
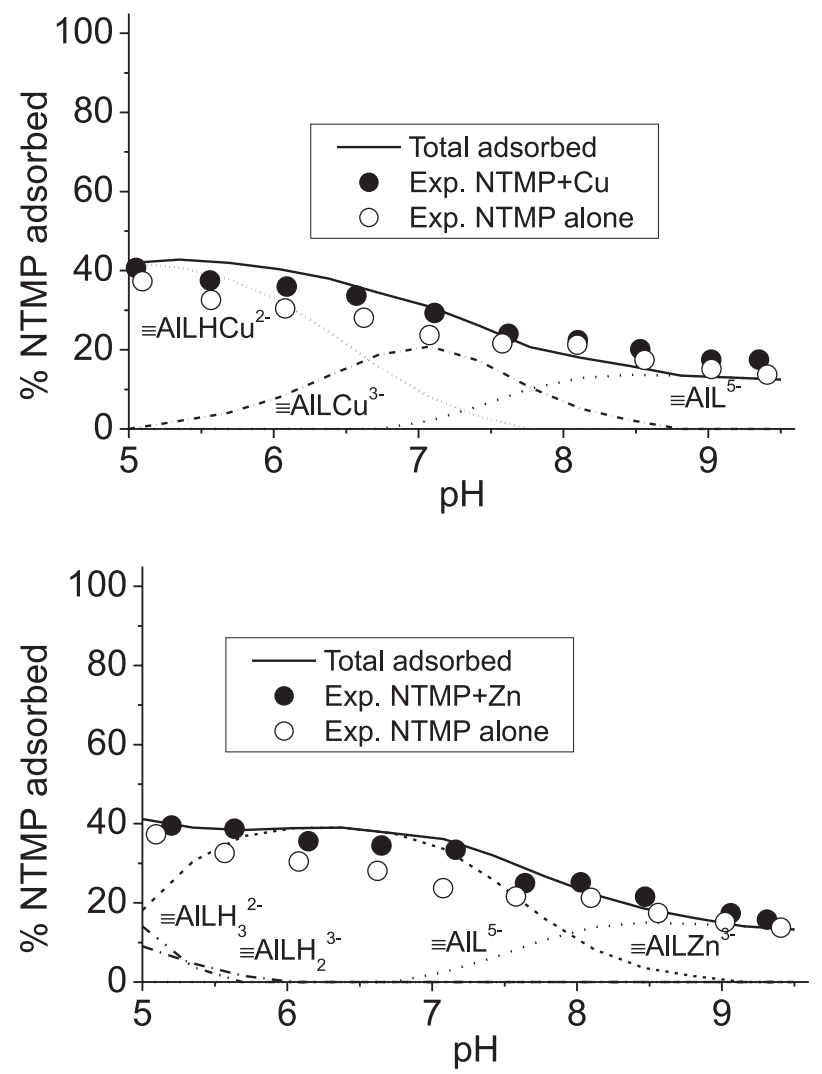

Figura 1S. Percentage NTMP $5 \times 10^{-4} \mathrm{M}$ adsorbed vs. $\mathrm{pH}$ in the presence of $\mathrm{Cu}(\mathrm{II})$ and $\mathrm{Zn}(\mathrm{II}) 5 \times 10^{-4} \mathrm{M}$. The curves are calculated using the constants from Table 1. Conditions: $1 \mathrm{~g} / \mathrm{L}$ boehmite, $0.1 \mathrm{M} \mathrm{NaNO}_{3}$ 
A
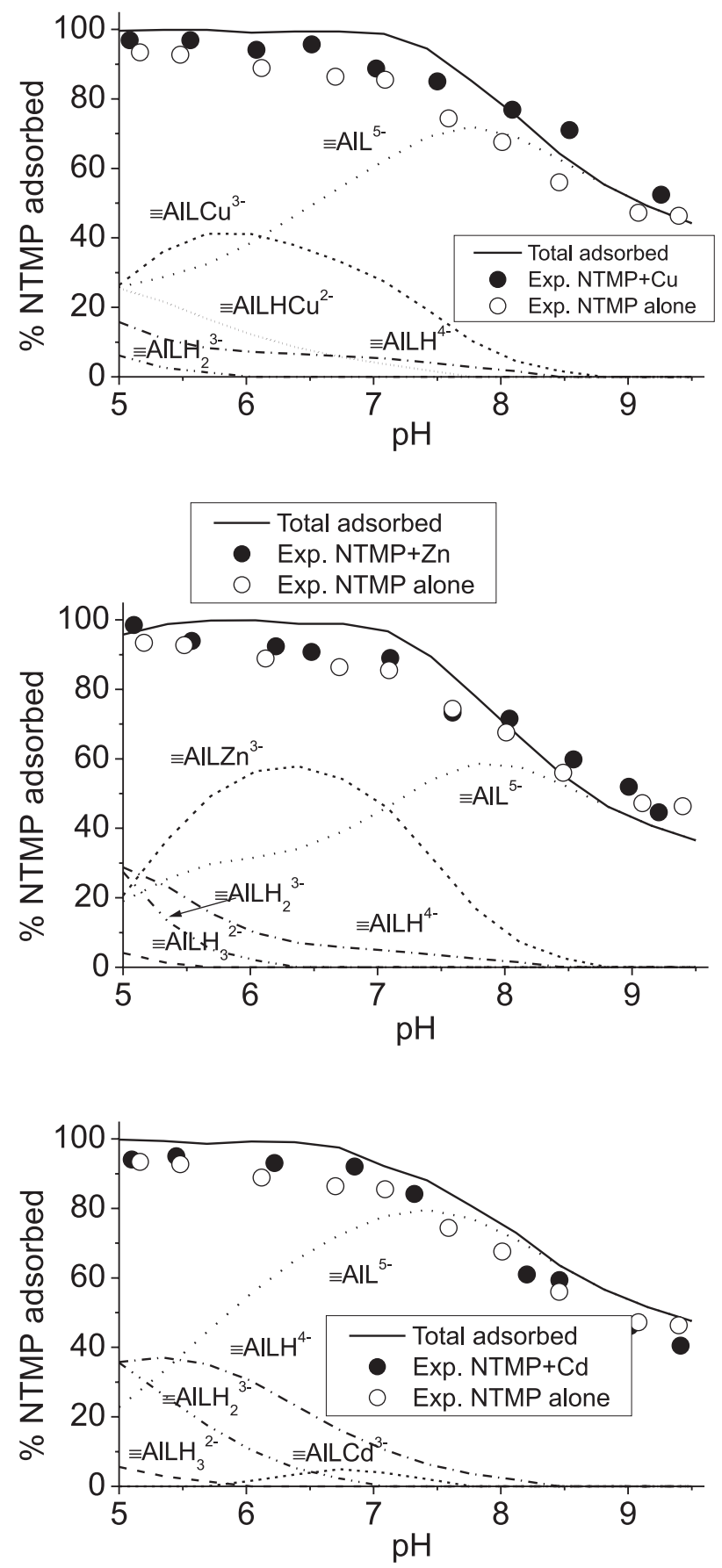

B
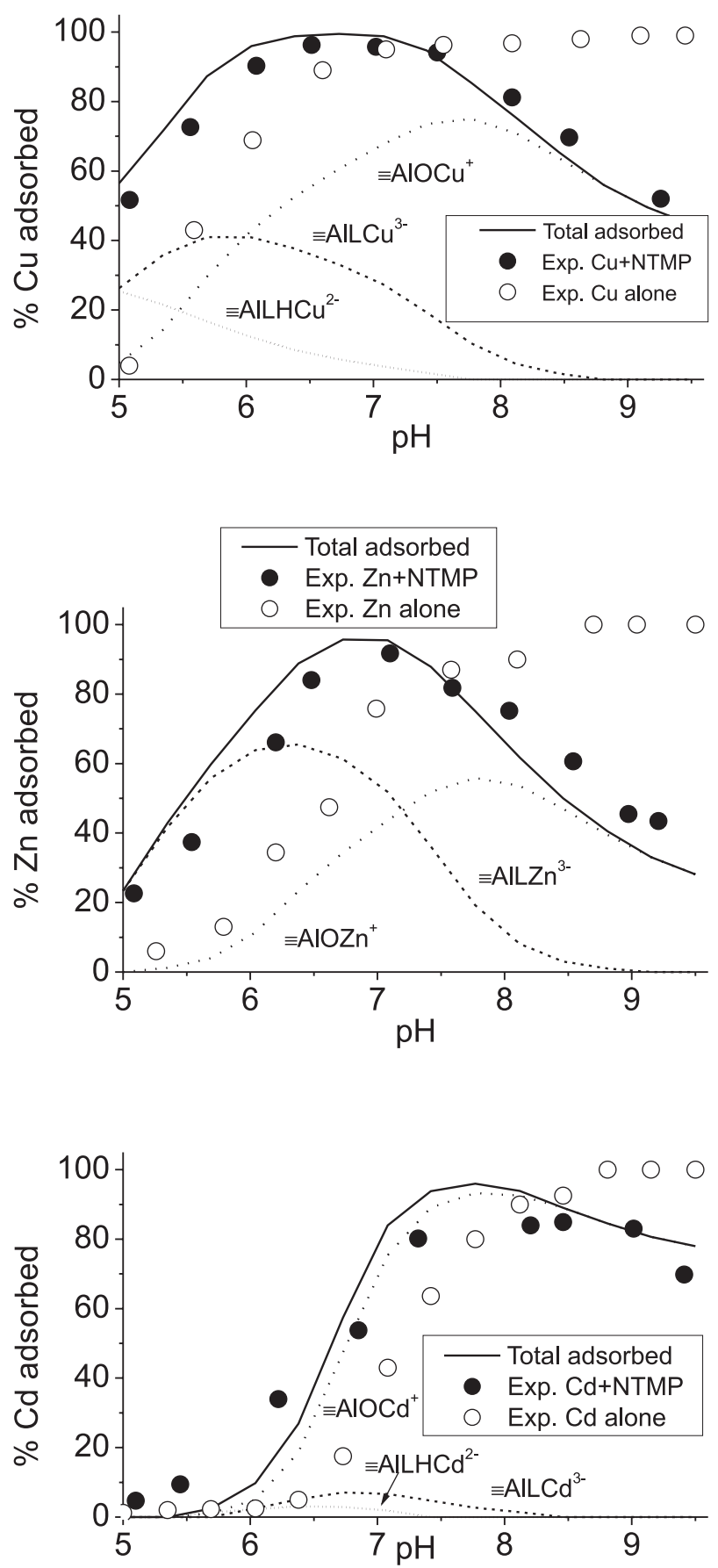

Figura 2S. A. Percentage NTMP $1 \times 10^{-4} \mathrm{M}$ adsorbed vs. $p H$ in the presence of $C u(I I), Z n(I I)$ and $C d(I I) 1 \times 10^{-4} \mathrm{M}$. The curves are calculated using the constants from Table 1. Conditions: $1 \mathrm{~g} / \mathrm{L}$ boehmite, $0.1 \mathrm{M} \mathrm{NaNO}_{3}$. B. Percentage Cu(II), $\mathrm{Zn}(\mathrm{II})$ and $\mathrm{Cd}(\mathrm{II}) 1 \times 10^{-4} \mathrm{M}$ adsorbed vs. pH in the presence of NTMP $1 \times 10^{-4} \mathrm{M}$. The curves are calculated using the constants from Table 1. Conditions: $1 \mathrm{~g} / \mathrm{L}$ boehmite, $0.1 \mathrm{M} \mathrm{NaNO}_{3}$ 

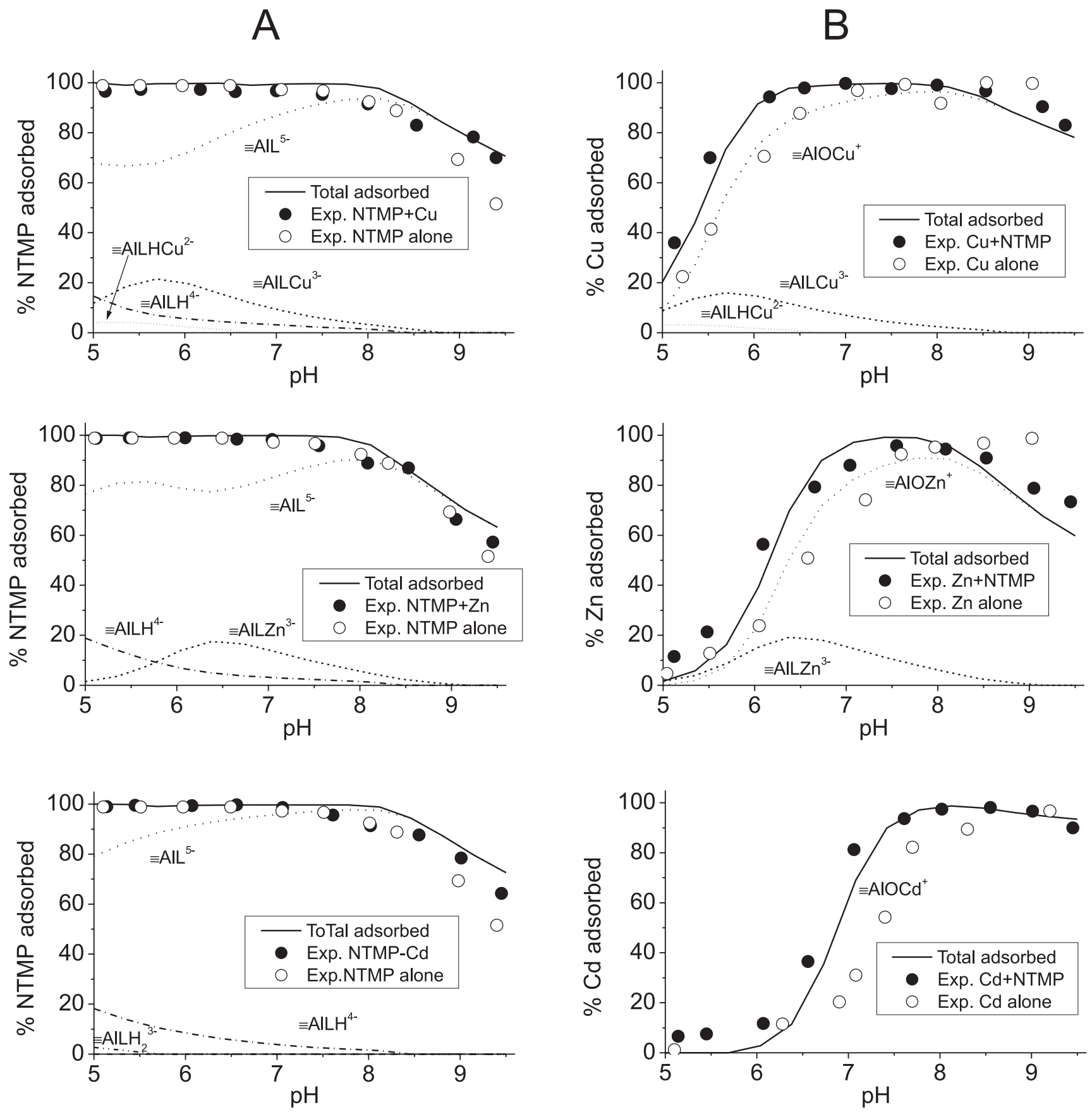

Figura 3S. A. Percentage NTMP $5 \times 10^{-5} \mathrm{M}$ adsorbed vs. $\mathrm{PH}$ in the presence of $\mathrm{Cu}(\mathrm{II}), \mathrm{Zn}(\mathrm{II})$ and $\mathrm{Cd}(\mathrm{II}) 5 \times 10^{-5} \mathrm{M}$. The curves are calculated using the constants from Table 1. Conditions: $1 \mathrm{~g} / \mathrm{L}$ boehmite, $0.1 \mathrm{M} \mathrm{NaNO}_{3}$. B. Percentage Cu(II), Zn(II) and Cd(II) $5 \times 10^{-5} \mathrm{M}$ adsorbed vs. $p H$ in the presence of NTMP $5 \times 10^{-5} \mathrm{M}$. The curves are calculated using the constants from Table 1. Conditions: $1 \mathrm{~g} / \mathrm{L}$ boehmite, $0.1 \mathrm{M} \mathrm{NaNO}_{3}$ 

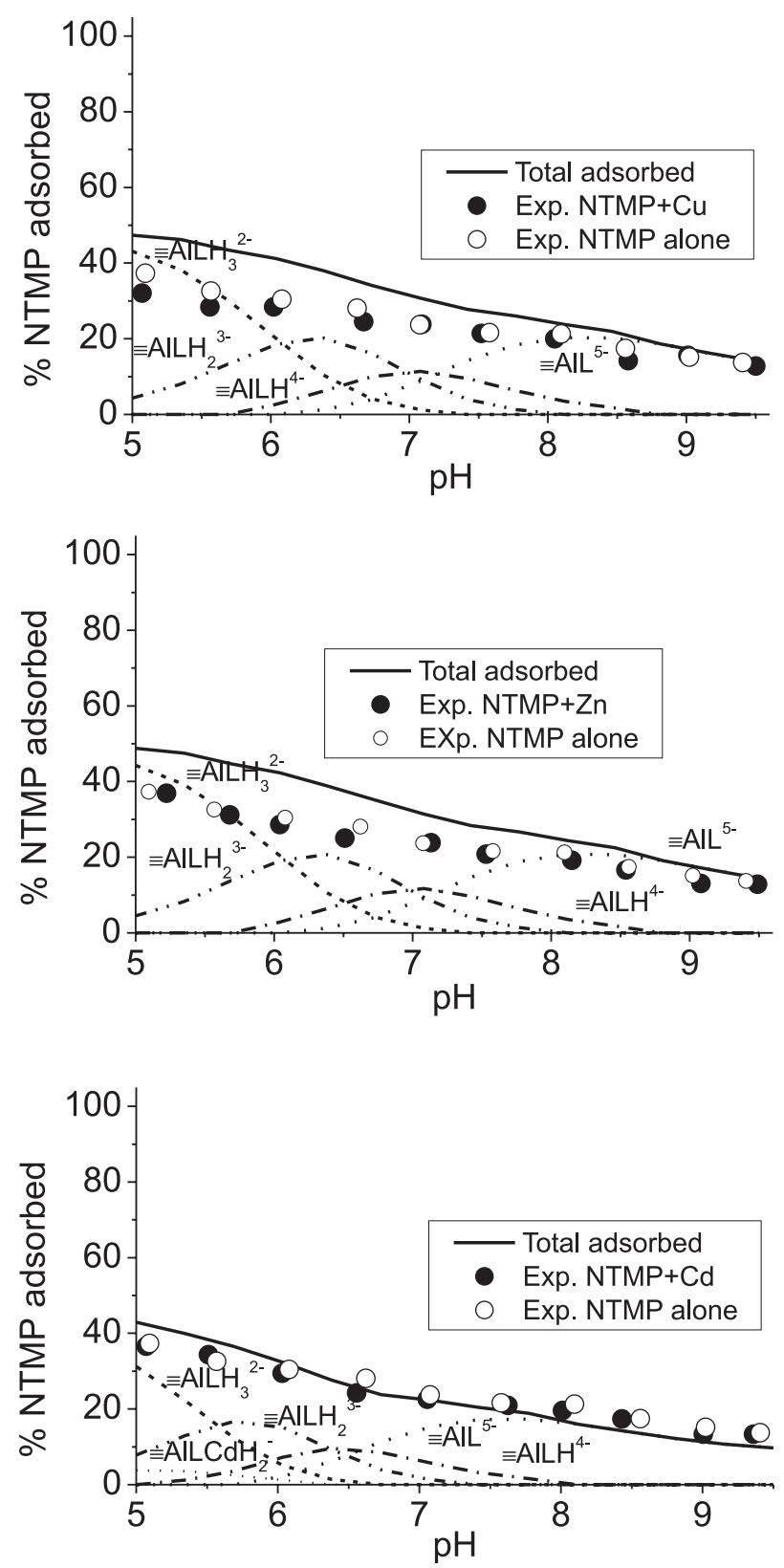

Figura 4S. Percentage NTMP $5 \times 10^{-4} \mathrm{M}$ adsorbed vs. pH in the presence of $\mathrm{Cu}(\mathrm{II}), \mathrm{Zn}(\mathrm{II})$ and $\mathrm{Cd}(\mathrm{II}) 1 \times 10^{-4} \mathrm{M}$. The curves are calculated using the constants from Table 1. Conditions: $1 \mathrm{~g} / \mathrm{L}$ boehmite, $0.1 \mathrm{M} \mathrm{NaNO}_{3}$ 
A
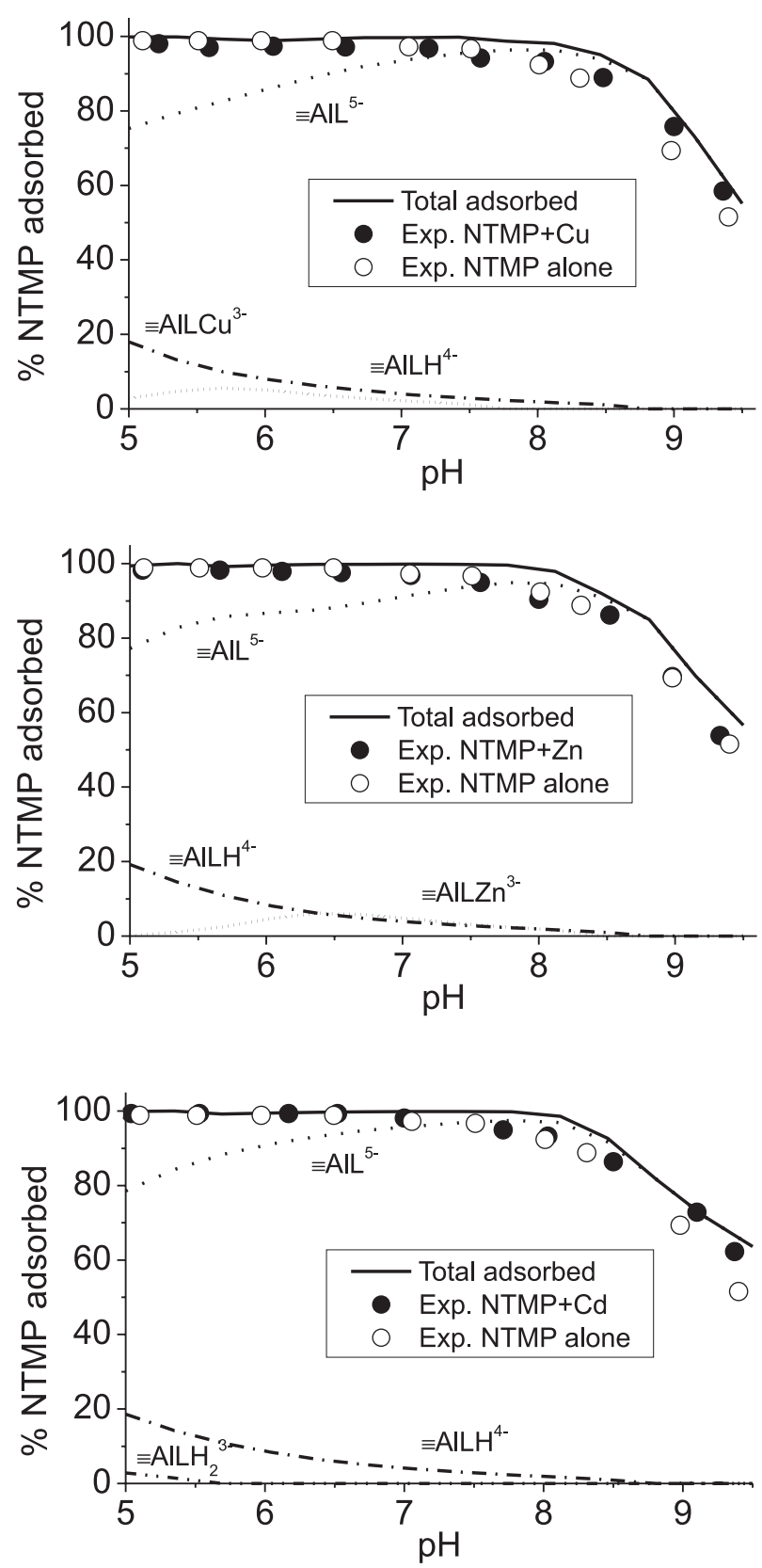

B

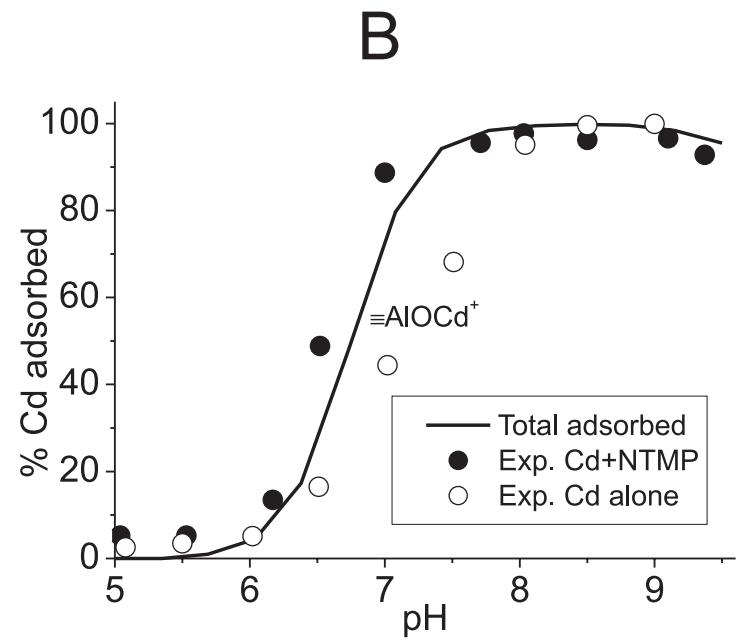

